\title{
Investigating the Effect of Gift-Giving on Patient's Behavior in the Pediatric Clinic of Dr. Sheikh Hospital of Mashhad
}

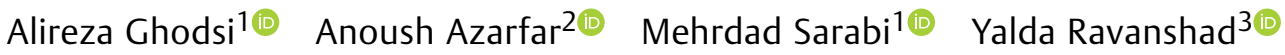 \\ Mohammad Esmaeeli ${ }^{4}$ Zeinab Salahi ${ }^{2}{ }^{\circledR}$
}

${ }^{1}$ Student Research Committee, Faculty of Medicine, Mashhad University of Medical Sciences, Mashhad, Iran

2 Kidney Transplantation Complications Research Center, Mashhad University of Medical Sciences, Mashhad, Iran

${ }^{3}$ Department of Community Medicine, Mashhad Branch, Islamic Azad University, Mashhad, Iran

${ }^{4}$ Department of Pediatrics, Mashhad University of Medical Sciences, Mashhad, Iran

Address for correspondence Yalda Ravanshad, Assistant Professor, Faculty of Medicine, Mashhad University of Medical Sciences, Azadi Square, Mashhad, Iran (e-mail: Yalda.ravanshad@gmail.com).

J Child Sci 2020;10:e215-e220.

\begin{abstract}
Keywords

- gift giving

- child

- social behavior

- physicians

Objective The aim of this study was to investigate the effect of gift-giving on the patient's behavior. We hypothesized that it is possible to improve the relationship between a doctor and a patient by giving the visiting patient gifts as such gesture may boost her confidence in the doctor, help built personable relationship, and thereby facilitate examination.

Materials and Methods For this study, we selected pediatric patients aged 3 to 12 years, who visited pediatric clinic of Dr. Sheikh Hospital of Mashhad. Patients were divided into two groups. One group received a gift (stickers) after examination and prescription. The criterion for evaluating patients' behavior was parental opinion, and the questionnaire was completed in two stages. The Chi-square test was used to compare the behavior of the patients, and data were analyzed by SPSS software.

Results In total, 194 people participated that included 74 boys and 120 girls. There was a significant difference at the $99 \%$ level between the control and intervention groups in the variables of stress, the desire to go to the doctor, fear reduction between visits, regular use of the drug, cooperation with the doctor, the desire for re-referral, and insistence on referring to the same physician after receiving the gift. There was also a significant difference at the $95 \%$ level between two groups in terms of the expression of physical problems by kids. However, there was no significant difference in the level of stress before the receipt of the gift, the desire and willingness to refer to the doctor before receiving the gift, and the waiting time tolerance to enter the doctor's room.

Conclusion We found that gifts motivate more appropriate behaviors in kids when referring to a doctor.
\end{abstract}

received

July 21,2020

accepted after revision

October 22, 2020
DOI https://doi.org/

10.1055/s-0040-1721449.

ISSN 2474-5871.
Copyright (c) 2020 Georg Thieme Verlag License terms

KG Rüdigerstraße 14, 70469 Stuttgart,

Germany (c) (i) 


\section{Introduction}

One of the challenges of physicians working with children is how to deal with visiting children by predicting their behavior and reactions to diagnostic and therapeutic measures. Familiarity with children's behavioral characteristics and the ability to predict how they function in different situations is critical to the success of the therapist, especially in the first visit. ${ }^{1,2}$ Every therapist who deals with children would be very willing to know the methods and criteria for predicting children's behavior and reactions to diagnostic and therapeutic measures. $^{3,4}$ In this regard, one of the best criteria is to identify easy and difficult behavioral symptoms in the child. ${ }^{5} \mathrm{~A}$ child can be called a difficult child, an easy child, or a combination of both in terms of innate and temperamental characteristics. ${ }^{6}$ According to Kaplan and Sadok, approximately $10 \%$ of children have difficult traits, and $40 \%$ have easy traits. ${ }^{7,8}$ An easy child shows the best behavior and cooperation with parents, caregivers, and therapists, while tolerating a difficult child and interacting with her is challenging and exhausting for everyone, even parents. ${ }^{9}$ One of the main reasons why children are mostly afraid of medical procedures is that their apprehension of the amount of pain and discomfort caused by the procedure before undergoing is very high and somewhat unrealistic. ${ }^{10}$ One of the challenges for the health care team is children's fear of the medical environment. Findings from previous studies have shown that if a child has previous bad experiences with medical care providers, her cooperation will reduce in subsequent examinations. ${ }^{11}$

According to the conditional learning theory, learning is a change process that occurs due to the conditions and triggers a reaction, where in children can be provoked by a gift..12,13 Giving a gift is a social, cultural, and economic experience, and it plays an important role in maintaining social relationships and expressing emotions. Gifts, both material and spiritual, have many psychological effects on both the giver and the recipient. ${ }^{14,15}$ According to existing reviews, a gift is known as a tangible object given by one person to another. In Freud's theory (1917), the concept of giving or receiving a gift has been mentioned, and according to it, the gift affects the individual's subconscious. ${ }^{16}$

Children are usually concerned about going to the doctor and are not willing to do it. There are thus issues such as children's fear and anxiety that can interfere with the treatment process, and therefore, it is a concern for parents. Giving-gifts is an easy, noninvasive, and low-cost method that not only does not usually interfere with medical treatments, but also may have very promising outcomes. It is a subject that has slightly been explored in the literature, we therefore intended to investigate the effect of gift-giving on patients' behavior when referring to pediatric clinics.

\section{Materials and Methods}

The present work is a cross-sectional study on children referred to the Clinic of Dr. Sheikh Pediatric Hospital in Mashhad from April 2017 to September 2017. To investigate the effect of gifts on patients' behavior when visiting a pediatric clinic, a researcher-made questionnaire with three subscales was designed to assess parents' opinion and their child's satisfaction with receiving a gift in the doctor's office, and the child's willingness to visit again. There were 12 questions, and each question was evaluated on a scoring scale (1-5): very high (1), high (2), medium (3), low (4), and very low (5). The questionnaire included demographic information and 12 questions about parent and child satisfaction with the visit. The validity of the questionnaire was confirmed by experts and its reliability by the Cronbach's $\alpha$ of 0.79 .

Among all 3- to 12-year-old children referred to the Clinic of Dr. Sheikh Pediatric Hospital, the ones whose parents were willing to participate in filling out the questionnaire were enrolled. After obtaining the informed consent, 194 patients entered the study and were randomly divided into two groups: intervention group (96) and control group (98). The first group included patients, who were given a gift (sticker) after examination and prescription, and its effect was examined on the child's second visit. A wide variety of stickers were available to subjects so that the patient had the power to choose. The second group was patients who did not receive a gift. A questionnaire was distributed to parents and completed in two steps: some questions completed during the initial visit and others either over the phone or in the next visit. The examiner and the type of examination were the same for all the patients. After completing the questionnaires, data were analyzed by IBM SPSS Statistics software version 20.0, and the Chi-square test was used to compare the behavior of patients in the control and intervention groups. The study protocol was fully approved by the ethics committee of Mashhad University of Medical Sciences (IR. MUMS.fm.REC.1394.588).

\section{Results}

To interpret the results, the mean and standard deviation are provided to describe quantitative data, and tables and graphs are used for qualitative data. This study was conducted on 194 children aged 3 to 12 years. There were 74 boys (38\%) and 120 girls (62\%). The average age of the children in the intervention group was $6.35 \pm 1.76$ years and in the control group was $6.40 \pm 1.84$ years. The minimum and maximum age of children in both intervention and control groups were 4 and 11 years, respectively. Out of the 194 questionnaires collected, $136(70.1 \%)$ were completed by mothers and 58 (29.9\%) by fathers. There was no significant difference between the two study groups in terms of completing the questionnaire by each parent.

The questionnaire used in this study, designed by the researchers, included demographic information and 12 questions about parent and child satisfaction with the visit, the validity of which was determined under the supervision of experts, and its reliability by Cronbach's $\alpha$ (equal to 0.79 ). In this questionnaire, the amount of stress and desire when referring, before and after giving a gift, was measured. The results showed that before presenting the gift, $18.6 \%$ of the children in the intervention group and $19.6 \%$ of the children 
in the control group had a high level of stress, and $8.8 \%$ in the intervention group and $7.2 \%$ in the control group had a very high level of stress. However, after presenting the gift, on the second visit, the very high and high stress levels of children in the intervention group decreased to 1.5 and $0.0 \%$, respectively. The frequency in the control group was 4.6 and $17 \%$, respectively. According to the Chi-square test, there was a statistically significant difference between the two groups for the stress level variable in the second visit $(p=0.0001)$.

The results of the study, according to - Table 1, showed that for the variable of children's desire in the first visit, the frequency of the very low and low categories in the intervention group was 14.9 and $14.4 \%$, and in the control group was 13.4 and $13.9 \%$, respectively. This level of desire for the intervention group decreased to 1 and $4.1 \%$ in the second visit-after receiving the gift-for the very low and low classes, respectively. According to the Chi-square test, two results showed that in the variable of children's desire to see a doctor in the second visit and after receiving the gift, there was a statistically significant difference between the two groups of intervention and control ( $p=0.0001$ ). Therefore, the children's interest in the intervention group to see a doctor increased.

In this study, as illustrated in -Table 2, the parents' opinion on the effect of gift on fear reduction, regular drug use, the child's level of cooperation with the doctor during the examination, and expression of physical problems by the child were evaluated. The results showed that between the intervention and control groups in the variables of reducing children's fear of the office ( $p=0.0001)$, regular use of drugs $(p=0.0001)$, the child's level of cooperation with the examiner $(p=0.0001)$, and expression of physical problems $(p=0.024)$, there was a statistically significant difference after receiving a gift.

In this study, the effect of giving a gift on the patient's desire to see a doctor again was also evaluated. The results showed that the frequency of the very high category in the intervention and control groups was 20.1 and $0 \%$, respectively. The Chisquare test score was 117.2 , and there was a statistically significant difference at the $99 \%$ level between the two groups in this variable $(p=0.0001)$. Therefore, accordingly, giving a gift increases the patient's desire to see the doctor again. In contrast, another variable that was examined was the patient's tolerance of waiting for entering the doctor's room. Comparing the two intervention and control groups, there was no significant difference $(p=0.263)$.

According to - Table 3, the effect of giving a gift on the child's insistence on visiting the same physician was also measured in this study, and there was a significant difference between the intervention and control groups $(p=0.0001)$.

At the end of the study, the parents' opinion about giving a gift to a patient and whether they recommend it to other doctors was examined. As shown in - Table 3 , most parents have advised doctors to give gifts to children: $58 \%$ of parents

Table 1 The results of the Chi-square test to compare the frequency of subscales of the questionnaire in the two groups of intervention and control (first group of variables)

\begin{tabular}{|c|c|c|c|c|}
\hline Variable & Category & $\begin{array}{l}\text { Intervention group } \\
(n=96)(\%)\end{array}$ & $\begin{array}{l}\text { Control group } \\
(n=98)(\%)\end{array}$ & Test result \\
\hline \multirow{5}{*}{$\begin{array}{l}\text { The level of stress before } \\
\text { receiving the gift }\end{array}$} & Very high & $17(8.8)$ & $14(7.2)$ & \multirow[t]{5}{*}{$p=0.83, X^{2}=0.881$} \\
\hline & High & $36(18.6)$ & 38 (19.6) & \\
\hline & Moderate & 27 (13.9) & 32 (16.5) & \\
\hline & Low & $16(8.2)$ & $14(7.2)$ & \\
\hline & Very low & $0(0)$ & $0(0)$ & \\
\hline \multirow{5}{*}{$\begin{array}{l}\text { The level of stress in the } \\
\text { second visit }\end{array}$} & Very high & $3(1.5)$ & $9(4.6)$ & \multirow{5}{*}{$\begin{array}{l}p=0.0001 \\
X^{2}=83.909\end{array}$} \\
\hline & High & $0(0)$ & $33(17.0)$ & \\
\hline & Moderate & $15(7.7)$ & $30(15.5)$ & \\
\hline & Low & 37 (19.1) & $26(13.4)$ & \\
\hline & Very low & $41(21.1)$ & $0(0)$ & \\
\hline \multirow{5}{*}{$\begin{array}{l}\text { Desire to see a doctor } \\
\text { (before receiving a gift) }\end{array}$} & Very high & $1(0.5)$ & $2(1)$ & \multirow{5}{*}{$\begin{array}{l}p=0.929 \\
X^{2}=0.871\end{array}$} \\
\hline & High & $17(8.8)$ & $18(9.3)$ & \\
\hline & Moderate & $21(10.8)$ & 25 (12.9) & \\
\hline & Low & $28(14.4)$ & 27 (13.9) & \\
\hline & Very low & 29 (14.9) & $26(13.4)$ & \\
\hline \multirow{5}{*}{$\begin{array}{l}\text { Desire to see a doctor } \\
\text { (after receiving a gift) }\end{array}$} & Very high & $39(20.1)$ & $5(2.6)$ & \multirow{5}{*}{$\begin{array}{l}p=0.0001 \\
X^{2}=46.518\end{array}$} \\
\hline & High & $23(11.9)$ & 25 (12.9) & \\
\hline & Moderate & $24(12.4)$ & $28(14.4)$ & \\
\hline & Low & $8(4.1)$ & $20(10.3)$ & \\
\hline & Very low & $2(1)$ & $20(10.3)$ & \\
\hline
\end{tabular}


Table 2 The Chi-square test results to compare the frequency of subscales of the questionnaire in the two groups of intervention and control (first group of variables)

\begin{tabular}{|c|c|c|c|c|}
\hline Variable & Category & $\begin{array}{l}\text { Intervention group (\%) } \\
(n=96)\end{array}$ & $\begin{array}{l}\text { Control group (\%) } \\
(n=98)\end{array}$ & Test result \\
\hline \multirow{5}{*}{$\begin{array}{l}\text { The effect of receiving } \\
\text { gifts on reducing } \\
\text { children's fear of the } \\
\text { doctor's office }\end{array}$} & Very high & $46(23.7)$ & $0(0.0)$ & \multirow{5}{*}{$\begin{array}{l}p=0.0001 \\
X^{2}=94.132\end{array}$} \\
\hline & High & $28(14.4)$ & $11(5.7)$ & \\
\hline & Moderate & $13(6.7)$ & $36(18.6)$ & \\
\hline & Low & $5(2.6)$ & 37 (19.1) & \\
\hline & Very low & $4(2.1)$ & $14(7.2)$ & \\
\hline \multirow{5}{*}{$\begin{array}{l}\text { The effect of receiving } \\
\text { gifts on regular drug } \\
\text { use }\end{array}$} & Very high & $16(8.2)$ & $0(0.0)$ & \multirow{5}{*}{$\begin{array}{l}p=0.0001 \\
X^{2}=40.223\end{array}$} \\
\hline & High & $19(9.8)$ & $3(1.5)$ & \\
\hline & Moderate & $30(15.5)$ & $32(16.5)$ & \\
\hline & Low & $20(10.3)$ & $49(25.3)$ & \\
\hline & Very low & $11(5.7)$ & $14(7.2)$ & \\
\hline \multirow{5}{*}{$\begin{array}{l}\text { The effect of the gift } \\
\text { on the child's } \\
\text { cooperation with the } \\
\text { doctor during the } \\
\text { examination }\end{array}$} & Very high & $5(2.6)$ & $1(0.5)$ & \multirow{5}{*}{$\begin{array}{l}p=0.0001 \\
X^{2}=30.848\end{array}$} \\
\hline & High & $24(12.4)$ & $3(1.5)$ & \\
\hline & Moderate & $39(20.1)$ & $35(18.0)$ & \\
\hline & Low & $19(9.8)$ & $45(23.2)$ & \\
\hline & Very low & $9(4.6)$ & $14(7.2)$ & \\
\hline \multirow{5}{*}{$\begin{array}{l}\text { The effect of the gift } \\
\text { on the patient's } \\
\text { expression of physical } \\
\text { problems }\end{array}$} & Very high & $5(2.6)$ & $0(0)$ & \multirow{5}{*}{$\begin{array}{l}p=0.024 \\
X^{2}=11.204\end{array}$} \\
\hline & High & $7(12.4)$ & $5(1.5)$ & \\
\hline & Moderate & $24(20.1)$ & $29(18.0)$ & \\
\hline & Low & $40(9.8)$ & $54(23.2)$ & \\
\hline & Very low & $20(4.6)$ & $10(7.2)$ & \\
\hline
\end{tabular}

in the intervention group and $53 \%$ of parents in the control group strongly recommended giving a gift to a child by a doctor (the very high category). Comparing the two groups, the test results showed that statistically, there was no significant difference between the two groups of intervention and control ( $p=0.319)$.

A sign test was used to compare the variables of stress and desire of the child to see a doctor before and after receiving the gift in the intervention group. Regarding the level of stress before and after receiving the gift, in 71 cases out of 96 patients studied (intervention group), the amount of stress was found to be decreased after receiving the gift, in 25 cases the level of stress did not change, and in none of them the stress level increased. For the level of child's desire to see a doctor before and after the gift, in 80 cases out of 96 children, the child's desire increased after receiving the gift and in 16 cases, no change was seen. It did not decrease in any of the cases. - Table 4 shows the results of the sign test for these two variables.

As can be seen in -Table 4, there was a significant difference between the two variables before and after receiving the gift.

\section{Discussion}

The fact that a child needs not only physical attention and care in childhood but also social, emotional, psychological, and mental development has been proven. Since the experience of hospitalization is stressful and unpleasant, children are more likely to not feel comfortable during this experience which may impact their feelings, desires, and level of happiness. Children need special care in hospitals and medical centers, and pediatric hospitals must have certain characteristics and procedures in place to meet the requirements for sick children and their families. One of these procedures can be giving a gift to children to make their hospital or doctor visit more pleasant. In the present study, an attempt was made to evaluate the effect of receiving a gift on the behavior of the patients who referred to the pediatric clinic. We had promising results that gift-giving can reduce children's fear and anxiety when referring to medical centers and increase children's cooperation with the medical team. We observed that the child's desire to see a doctor again increased. The children took their medication more regularly. Due to the reduction of fear, the child's expression of physical problems also improved. Parents also strongly recommended giving a gift to a child by a doctor, and interestingly, there was no significant difference between the control and intervention groups regarding this variable.

In some cases, a gift is a reward for taking a step forward in the treatment process. Such a gift may be chosen to reinforce therapeutic goals because of its symbolic nature. ${ }^{17}$ Rank pointed it out by describing a 5-year-old boy, who received a gun as a gift after being vaccinated. ${ }^{18}$ This gift was chosen 
Table 3 The results of the Chi-square test to compare the frequency of subscales of the questionnaire in the two groups of intervention and control (third group of variables)

\begin{tabular}{|c|c|c|c|c|}
\hline Variable & Category & Intervention group & Control group & Test result \\
\hline \multirow{5}{*}{$\begin{array}{l}\text { The effect of the gift } \\
\text { on the patient's desire } \\
\text { for the next visit }\end{array}$} & Very high & $39(20.1)$ & $0(0)$ & \multirow{5}{*}{$\begin{array}{l}p=0.0001 \\
X^{2}=117.2\end{array}$} \\
\hline & High & $38(19.6)$ & $5(2.6)$ & \\
\hline & Moderate & $11(5.7)$ & $26(13.4)$ & \\
\hline & Low & $4(2.1)$ & $46(23.7)$ & \\
\hline & Very low & $4(2.1)$ & $21(10.8)$ & \\
\hline \multirow{5}{*}{$\begin{array}{l}\text { The patient's } \\
\text { tolerance for entering } \\
\text { the doctor's room }\end{array}$} & Very high & $9(4.6)$ & $11(5.7)$ & \multirow{5}{*}{$\begin{array}{l}p=0.263 \\
X^{2}=5.251\end{array}$} \\
\hline & High & $6(3.1)$ & $3(1.5)$ & \\
\hline & Moderate & $33(17.0)$ & $22(11.3)$ & \\
\hline & Low & $30(15.5)$ & $37(19.1)$ & \\
\hline & Very low & $18(9.3)$ & 25 (12.9) & \\
\hline \multirow{5}{*}{$\begin{array}{l}\text { The child's insistence } \\
\text { on seeing the same } \\
\text { doctor }\end{array}$} & Very high & $36(18.6)$ & $0(0.0)$ & \multirow{5}{*}{$\begin{array}{l}p=0.0001 \\
X^{2}=102.6\end{array}$} \\
\hline & High & $40(20.6)$ & $8(4.1)$ & \\
\hline & Moderate & $9(4.6)$ & $32(16.5)$ & \\
\hline & Low & $7(3.6)$ & $44(22.7)$ & \\
\hline & Very low & $4(2.1)$ & $14(7.2)$ & \\
\hline \multirow[t]{5}{*}{ Parents' advice } & Very high & 58 (29.9) & $53(27.3)$ & \multirow[t]{5}{*}{$p=0.319, X^{2}=4.705$} \\
\hline & High & $28(14.4)$ & $36(18.6)$ & \\
\hline & Moderate & $4(2.1)$ & $4(2.1)$ & \\
\hline & Low & $3(1.5)$ & $5(2.6)$ & \\
\hline & Very low & $3(1.5)$ & $0(0.0)$ & \\
\hline
\end{tabular}

because the subject overcame his fear of vaccination and strengthened his sense of masculinity. In the study of Spandler et al, they designed a qualitative questionnaire on the role of giving and receiving gifts in treatment. ${ }^{19}$ The questionnaires were completed by 80 therapists, most of whom were psychoanalysts. Gifts included food and drink, flowers, books, or handicrafts. The results showed that accepting gifts or refusing to receive gifts can both be harmful and requires further research. ${ }^{19}$ However, as in our work, this study has also shown that gifts can provide positive therapeutic experiences, and in addition to their therapeutic role, they can have other benefits such as the feeling of gratitude, emotional dialogue, and more cooperation with the doctor.

Children's behavior in social occasions including interaction with a health care team is believed to be led by the family culture and education. However, the research question was

Table 4 Sign test results for two variables of stress level and desire level to refer to the doctor, before and after the intervention

\begin{tabular}{|l|l|l|l|l|}
\hline \multirow{2}{*}{ Variable } & \multicolumn{2}{|l|}{ Frequency } & \multirow{2}{*}{-Value } \\
\cline { 2 - 4 } & $\begin{array}{l}\text { Before } \\
<\text { after }\end{array}$ & $\begin{array}{l}\text { Before } \\
=\text { after }\end{array}$ & $\begin{array}{l}\text { Before } \\
>\text { after }\end{array}$ & \\
\hline Stress & 0 & 25 & 71 & 0.0001 \\
\hline $\begin{array}{l}\text { Desire to see } \\
\text { a doctor }\end{array}$ & 80 & 26 & 0 & 0.0001 \\
\hline
\end{tabular}

how the doctor's actions such as gift giving may affect it. In a 2004 study in Mashhad Neamatollahi et al evaluated the relationship between children's behavior and maternal personality traits in 104 children visiting a dentist. ${ }^{20}$ It was concluded that the level of children's cooperation was only affected by the mother's personality in the first session, and over time as well as in the next sessions, the effect of the mother's personality traits on the children's cooperation reduced and factors such as the behavior of the dentist and her assistant, and the environment of the dental office had the greatest impact on the child's cooperation. Gift-giving can be among those behaviors and actions, and we showed in this study that giving gifts to children reduced their fear and stress when they went to the doctor, and the child's desire to see the same doctor again increased.

In a study done in Croatia, Kos recently reported the impact of giving and receiving gifts on the patient-physician relation. They considered all types of gifts even the monetary ones and concluded that gift-giving seems to be more common than expected as they can increase the sense of gratitude in both parties. ${ }^{21}$

It is worth noting that in addition to gift-giving, other methods for reducing the children's fear and stress and increasing their cooperation in medical venues have also been suggested. For example, in a study conducted by Aminabadi et al, reading illustrated stories for children aged 6 to 7 years before dental visits was reported to significantly increase children's cooperation. ${ }^{22}$ In two other studies, Wright 
and Graziano and Diament both reported that complementary methods such as textbooks and video clips of role-playing classes were educationally effective; even though studies have shown that these complementary methods, despite their significant benefits for parental awareness, may not have a definite effect on children's behavior. ${ }^{23,24}$ In our work, the studied behavioral encouragement was gift-giving that, like these two studies, had a positive influence on children's behavior.

As also indicated in the recent work by Kos, ${ }^{21}$ the topic of gift-giving and its effect on children behavior visiting medical care venues has very slightly been covered in the literature, despite its importance and promising results that it may bring. This was the motivation to consider this research work, and our main contribution is to statistically show the important role that gift-giving may play in pediatrics. On the other side, we were limited to older references. The other limitation of our study is the low variety of gifts. In addition, we did not assess the stress level in children before receiving gifts.

\section{Conclusion}

According to the results of our study, to reduce children's fear and anxiety when referring to medical centers, and to increase children's cooperation with the doctor for examination and treatment, gift-giving is a proper and accessible method. It can also be studied in larger populations with different age groups and different types of gifts and in other specialties, other than children.

\section{Conflict of Interest}

None declared.

\section{Acknowledgments}

This article was derived from the M.D. thesis by Zeinab Salahi (941003). The authors express their gratitude to all colleagues and nurses who assisted in this work.

\section{References}

1 Parke R. Child Psychology: A Contemporary Viewpoint. McGrawHill Higher Education; 2008

2 Brill WA. Behavior of pediatric dental patients throughout the course of restorative dental treatment in a private pediatric dental practice. J Clin Pediatr Dent 2001;26(01):55-60

3 Wilson S. Management of child patient behavior: quality of care, fear and anxiety, and the child patient. Pediatr Dent 2013;35(02): $170-174$
4 Lia ÉN, Costa VP. Child Behavioral Management. Pediatric Restorative Dentistry. Springer; 2019:13-21

5 Caroly S, Kaplan H, Sadock B. Comprehensive textbook of psychiatry. Child Psychiatr 2000;2:25-40

6 Kaplan HI, Sadock BJ, Grebb JA. Kaplan and Sadock's Synopsis of Psychiatry: Behavioral Sciences, Clinical Psychiatry. Williams \& Wilkins Co; 2007

7 Kaplan H, Sadock B. Synopsis of Psychiatry. 9th Edition. Philadelphia: Lippincott Williams \& Wilkins; 2003

8 Robert AK, Mary E. Psychiatric examination of the infant child and adolescent. In: Kaplan H, Sadock B, eds. Comprehensive textbook of psychiatry V2. 7th ed. Lippincott press; 2000:2572

9 Sadock B, Ruiz P. Kaplan \& Sadock's Synopsis of Psychiatry: Behavioral Sciences. Walters Kluwer; 2015

10 Pelander T, Leino-Kilpi H, Katajisto J. Quality of pediatric nursing care in Finland: children's perspective. J Nurs Care Qual 2007;22 (02):185-194

11 Proczkowska-Björklund M, Runeson I, Gustafsson PA, Svedin CG Communication and child behaviour associated with unwillingness to take premedication. Acta Paediatr 2008;97(09): 1238-1242

12 Basri H, Amin S, Umiyati M, Mukhlis H, Irviani R. Learning theory of conditioning. Learning 2020;7(08):2020

13 Pelaez M, Monlux K. Operant conditioning methodologies to investigate infant learning. Eur J Behav Anal 2017;18(02): 212-241

14 Graycar A, Jancsics D. Gift giving and corruption. Int J Public Adm 2017;40(12):1013-1023

15 Joy A. Gift giving in Hong Kong and the continuum of social ties. J Consum Res 2001;28(02):239-256

16 Freud S. On transformations of instinct as exemplified in anal erotism. The Standard Edition of the Complete Psychological Works of Sigmund Freud, Volume XVII. Infantile Neurosis Other Works 1917-19191955:125-134

17 Levin S, Wermer $\mathrm{H}$. The significance of giving gifts to children in therapy. J Am Acad Child Psychiatry 1966;5(04):630-652

18 Smolar AI. When we give more: reflections on intangible gifts from therapist to patient. Am J Psychother 2003;57(03):300-323

19 Spandler H, Burman E, Goldberg B, Margison F, Amos T. A doubleedged sword: understanding gifts in psychotherapy. Eur J Psychother Counsell 2000;3(01):77-101

20 Neamatollahi H, Tabatabaie S, Shakerimanesh F. Evaluation of the relationship between behavior of children in pediatric dental clinic and their mothers' personality. J Mashhad Dent Sch 2004; 28:111-118

21 Kos V. Material and non-material gifts from general practitioners to their patients. Acta Morphol 2016;13(01):40-46

22 Aminabadi NA, Vafaei A, Erfanparast L, Oskouei SG, Jamali Z. Impact of pictorial story on pain perception, situational anxiety and behavior in children: a cognitive-behavioral schema. J Clin Pediatr Dent 2011;36(02):127-132

23 Wright L. Indirect treatment of children through principle-oriented parent consultation. J Consult Clin Psychol 1976;44(01):148

24 Graziano AM, Diament DM. Parent behavioral training. An examination of the paradigm. Behav Modif 1992;16(01):3-38 